\title{
PENGARUH UKURAN PERUSAHAAN DAN UMUR PERUSAHAAN TERHADAP SAHAM INITIAL PUBLIC OFFERING (IPO) SEKTOR KEUANGAN
}

\author{
Wahyu Surya Putra S. \\ Fakultas Ilmu Sosial dan Ilmu Politik, Universitas Tomakaka Mamuju \\ E-mail: hyu.sp577@gmail.com
}

\begin{abstract}
ABSTRAK
Para investor yang melakukan investasi dengan membeli saham di pasar modal akan menganalisis mengenai kondisi perusahaan terlebih dahulu agar investasi yang di lakukan dapat memberikan keuntungan. Dalam melakukan analisis akan saham ada banyak jenis analisis yang di lakukan terutama dalam hal membeli saham yang akan melakukan IPO itu sendiri. Keterbatasan informasi dalam analisis saham yang melakukan IPO ini sering terjadi yang dimana informasi ini sangat di butuhkan dalam menentukan keputusan nantinya. Penelitian ini memiliki tujuan untuk mengetahui pengaruh Ukuran Perusahaan dan Umur Perusahaan Terhadap harga saham perusahaan yang melakukan Initial Public Offering (IPO) sector keuagan. Penelitian ini menggunakan pendekatan kuantitatif. Pengambilan sampel menggunakan metode nonprobability sampling yang cara pengambilan sampelnya digunakan teknik sampling purposive. Data yang digunakan adalah data sekunder yang diperoleh dari laporan Perpektus Perusahaan yang melakukan IPO di Bursa Efek Indonesia. Analisis data yang digunkan dalam penelitian ini adalah analisis regresi linier berganda dan juga uji asumsi. Hasil penelitian ini menunjukkan bahwa pengaruah Ukuran Perusahaan berpengaruh secara Positif dan juga Signifikan terhadap Harga Saham dan Umur Perusahaan juga berpengaruh Secara Positif dan Signifikan Terhadap Harga saham.
\end{abstract}

Kata Kunci: Harga saham; ukuran perusahaan; umur perusahaan 


\section{PENDAHULUAN}

Pertumbuhan ekonomi yang semakin pesat dan diiringi peningkatan jumlah penduduk serta semakin majunya teknologi menyebabkan industri perdagangan terus mengalami pertumbuhan. Hal tersebut menimbulkan persaingan antara perusahaan, hingga membuat perusahaan melakukan berbagai cara untuk terus eksis dibidangnya. Salah satu hal yang dapat dilakukan oleh perusahaan dalam rangka mengembangkan usahanya adalah dengan memenuhi kebutuhan modalnya (Junaeni, 2013). Cara yang ditempuh oleh perusahaan untuk menjadikan perusahaan tersebut untuk terus eksis adalah dengan menjadi perusahaan tersebut menjadi perusahaan terbuka hingga saham perusahaan dapat dibeli oleh masyarakat umum dengan menambah jumlah kepemilikan saham melalui penerbitan saham baru. Hal ini dapat dilakukan antara lain dengan menjual sahamnya kepada masyarakat umum melalui bursa efek.

Bursa efek bukan sekedar sebagai wahana sumber pembiayaan, tetapi juga sebagai sarana investasi yang melibatkan seluruh potensi dana masyarakat, baik yang tersedia di dalam negeri maupun dana yang tersedia di luar negeri. Pemanfaatan keberadaan bursa efek sebagai sarana investasi bukan cuma pemodal lokal tetapi juga pemodal asing. ktivitas pasar modal yang merupakan salah satu potensi perekonomian nasional, memiliki peranan yang penting dalam menumbuh kembangkan perekonomian nasional (Khairan, 2019). Dukungan sektor swasta menjadi kekuatan nasional sebagai dinamisator aktivitas perekonomian nasional (Savira \& Rimbano, 2016)

Bursa efek dapat memenuhi kebutuhan dana, baik bagi swasta maupun pemerintah dan BUMN (Armereo et al., 2020). Dengan demikian fungsi dari bursa efek adalah mengalokasikan secara efisien arus dana dari unit ekonomi yang mempunyai surplus tabungan (saving surplus unit) kepada unit ekonomi yang mempunyai defisit tabungan (saving deficit unit). Selain itu pasar modal secara makro ekonomi merupakan sarana pemerataan pendapatan, juga berfungsi sebagai motivator bagi emiten untuk meningkatkan kualitas output perusahaan dan bagi investor merupakan salah satu alternatif investasi (Ahmad, 2018). Penawaran saham perusahaan kepada masyarakat melalui bursa efek disebut proses go public. (Abdullah, 2018; Hendrasih, 2017) Transaksi penawaran umum penjualan saham perdana atau disebut IPO (Initial Public Offering) untuk pertama kalinya terjadi di pasar perdana (Primary Market) kemudian saham dapat diperjualbelikan di bursa efek, yang disebut dengan pasar sekunder (Secondary Market). Harga saham yang akan dijual perusahaan pada pasar perdana ditentukan oleh kesepakatan antara emiten (perusahaan penerbit) dengan underwriter (penjamin emisi), sedangkan harga saham yang dijual pada pasar sekunder ditentukan oleh mekanisme pasar, yaitu permintaan dan penawaran.

Para investor yang melakukan investasi dengan membeli saham di pasar modal akan menganalisis mengenai kondisi perusahaan terlebih dahulu agar investasi yang di lakukan dapat memberikan keuntungan. Dalam melakukan analisis akan saham ada banyak jenis analisis yang di lakukan terutama dalam hal 
membeli saham yang akan melakukan IPO itu sendiri. Keterbatasan informasi dalam analisis saham yang melakukan IPO ini sering terjadi yang dimana informasi ini sangat di butuhkan dalam menentukan keputusan nantinya.

Informasi atau indikator dalam mengalisis saham yang IPO itu sendiri dapat di lihat dari dari ukuran perusahaan dan umur perusahaan itu sendiri. Ukuran perusahaan adalah suatu ukuran, skala atau variabel yang menggambarkan besar kecilnya perusahaan berdasarkan beberapa ketentuan, seperti total aktiva, log size, nilai pasar, saham, total penjualan, total pendapatan, total modal dan lain-lain (Hermuningsih, 2012; Putranto \& Darmawan, 2018). Pengelompokan perusahaan atas dasar skala operasi umumnya terbagi menjadi tiga kategori, yaitu: perusahaan besar (large firm), perusahaan menengah (medium-size) dan perusahaan kesil (small firm). Ukuran perusahaan merupakan suatu skala yang dapat dihitung dengan tingkat total aset dan penjualan yang dapat menunjukkan kondisi perusahaan dimana perusahaan lebih besar akan mempunyai kelebihan dalam sumber dana yang diperoleh untuk membiayai investasinya dalam memperoleh laba. Ukuran perusahaan dapat digunakan untuk mewakili karakteristik keuangan perusahaan. Perusahaan besar yang sudah well estabilished akan lebih mudah memperoleh modal di pasar modal dibanding dengan perusahaan kecil. Karena kemudahan akses tersebut berarti perusahaan besar memiliki fleksibilitas yang lebih besar. Sedangkan umur perusahaan itu sendiri melihat seberapa lama perusahaan tersebut berdiri. Penelitian ini memiliki tujuan untuk mengetahui pengaruh Ukuran Perusahaan dan Umur Perusahaan Terhadap harga saham perusahaan yang melakukan Initial Public Offering (IPO) sector keuagan Penelitian ini memiliki tujuan untuk mengetahui pengaruh Ukuran Perusahaan dan Umur Perusahaan Terhadap harga saham perusahaan yang melakukan Initial Public Offering (IPO) sector keuagan.

\section{Metode Penelitian}

Penelitian ini adalah penelitian kuantitatif. Analisis data adalah proses penyederhanaan data agar lebih mudah dibaca dan diimplementasikan. Analisis data yang digunakan dalam penelitian ini adalah analisis regresi linear berganda yang digunakan untuk mengetahui hubungan antara variabel dependen dengan variabel independen dengan menggunakan aplikasi SPSS. Setelah itu selanjutnya akan dilakukan, data di uji terlebih dahulu dengan menggunakan uji asumsi klasik, untuk memastikan model regresi yang digunakan tidak terdapat masalah normalitas, multikolinearitas, heteroskedastisitas, dan autokorelasi.

\section{Hasil dan Pembahasan}

Pengujian asumsi klasik digunakan sebelum melakukan pengujian regresi linier berganda yang dilakukan untuk menguji hipotesis. Adapun pengujian yang digunakan adalah sebagai berikut: 


\section{Uji Normalitas}

Uji normalitas bertujuan untuk menguji apakah dalam suatu model regresi linier variabel terikat dan variabel bebas keduanya mempunyai distribusi normal atau tidak.Model regresi yang baik adalah yang memiliki distribusi data normal atau mendekati normal (Ghozali, 2001).

Alat analisis yang digunakan dalam uji ini adalah menggunakan histogram dan plot normal.Dasar pengambilan keputusan normal atau tidaknya data yang diolah adalah jika sebaran data menyebar merata ke semua daerah kurva normal, sehingga dapat disimpulkan bahwa data mempunyai distribusi normal. Demikian juga dengan output normal plot bahwa sebaran data mendekati garis normal atau di seitar garis diagonal dan mengikuti arah garis diagonal, sehingga dapat disimpulkan bahwa data mempunyai distribusi normal.

\section{Gambar 1}

\section{Uji Normalitas}

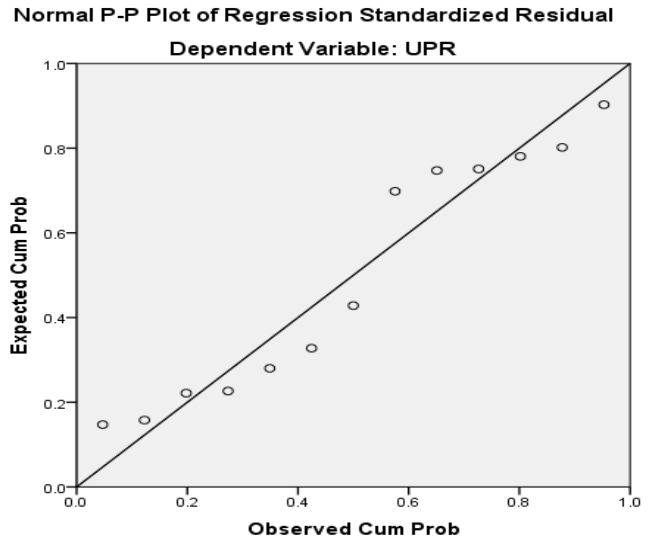

Berdasarkan uji normalitas dengan menggunakan bantuan SPSS 24 terlihat dari grafik di atas penyebaran data (titik) pada sumbu diagonal mengikuti arah garis diagonal sehingga dapat disimpulkan bahwa model regresi memenuhi asumsi normalitas.

\section{Uji Multikolinieritas.}

Uji multikolonieritas bertujuan untuk menguji apakah dalam model regresi ditemukan adanya korelasi antar variabel bebas. Untuk mendeteksi adanya problem multikoloneritas, maka dapat dilakukan dengan melihat nilai tolerance dan Variance Inflation Factor (VIF) serta besaran korelasi antar variabel independen. Berikut ini adalah tabel yang menunjukkan hasil uji multikolonieritas 
Kunuz: Journal of Islamic Banking and Finance Vol. 1, No. 1 (2021): 44-52

Tabel 1 Uji

\section{Multikolonieritas}

\begin{tabular}{lrr} 
Model & \multicolumn{2}{c}{ Collinearity Statistics } \\
& Tolerance & VIF \\
1 (Constant) & .950 & 1.052 \\
Ukuran & .950 & 1.052 \\
Umur & .950
\end{tabular}

Sumber: Output SPSS versi 24 (data diolah)

Dari data statistic kolineritas, diperoleh Variance Inflation Factor (VIF) dari seluruh variabel bebas yaitu $\mathrm{VIF}<10$, artinya tidak terjadi multikolineritas. Sebagaimana ditunjukkan pada table yaitu bahwa VIF untuk Ship's Call adalah 1,052 dan nilai VIF untuk Tarif sebesar 1.052. Dengan demikian dapat disimpulkan bahwa kedua variabel ini tidak mengalami multikolineritas karena VIF seluruh variabel berada pada nilai lebih kecil dari $10(\mathrm{VIF}<10)$.

\section{Uji Heterokedastisitas}

Uji Heterokedastisitas bertujuan untuk mengetahui apakah dalam model regresi terjadi ketidaksamaan varians dari residual atau pengamatan ke pengamatan yang lain. Pengujian heterokedastisitas dapat dilakukan dengan melihat grafik scatterplot. Apabila titik-titik pada grafik scatter plot menyebar dan berpola tidak teratur maka dapat diindikasikan bahwa model regresi bebas dari masalah heterokedastisitas. 
Kunuz: Journal of Islamic Banking and Finance Vol. 1, No. 1 (2021): 44-52 Website: http://ejournal.iain-manado.ac.id/index.php/kunuz

Gambar 2

Uji Heteroskedastisitas

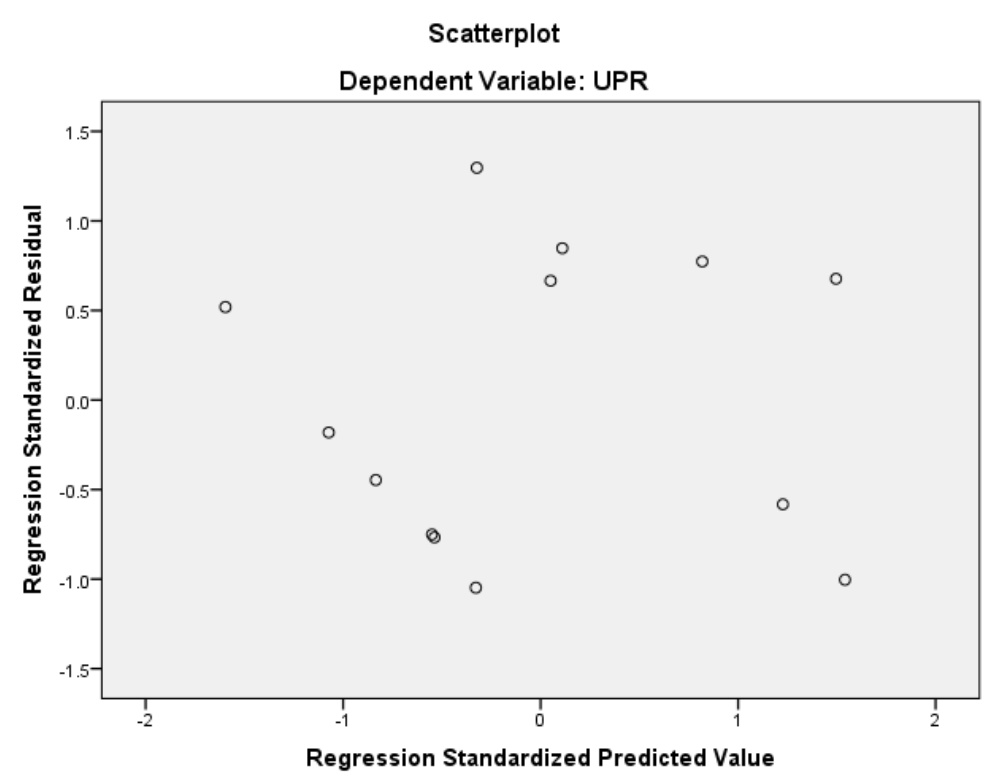

Hasil output gambar diatas dapat dilihat bahwa titik-titik menyebar secara acak dan berpola tidak teratur diindikasikan bahwa model regresi bebas dari heterekedastisitas.

\section{Uji Autokorelasi}

ini bertujuan untuk menguji apakah dalam suatu model regresi linier terdapat korelasi antara kesalahan pengganggu pada periode $t$ dengan kesalahan pada periode t-1. Autokorelasi muncul karena adanya observasi yang berurutan sepanjang waktu yang berkaitan satu sama lainnya. Untuk mengetahui ada atau tidaknya autokorelasi dapat dilihat melalui uji D-W dengan ketentuan sebagai berikut :

a) DW kurang dari 1.10, artinya ada kolerasi

b) DW kurang $1.10-1.54$, artinya tidak ada kesimpulan

c) DW kurang $1.55-2.56$, artinya tidak ada autokorelasi

d) DW kurang $2.57-2.90$, artinya tidak ada kesimpulan

e) DW lebih dari 2.90, artinya ada autokorelasi 
Tabel 3

\section{Uji Autokorelasi}

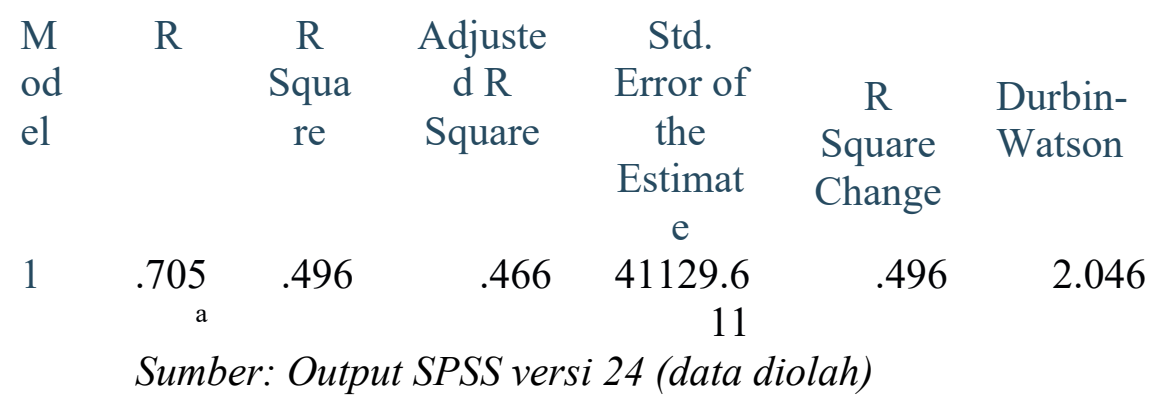

Dari pengujian Durbin-Watson pada tabel diatas diatas dapat dilihat nilai yang dihasilkan sebesar 2.046 yaitu berada diantara $1.55-2.56$ yang berarti bahwa tidak ada autokorelasi.

\section{Analisis Regresi Berganda}

\section{Tabel 4}

Analisis Regresi Berganda

\begin{tabular}{|c|c|c|c|c|c|c|}
\hline \multirow[t]{2}{*}{ Model } & & \multicolumn{2}{|c|}{$\begin{array}{l}\text { Unstandardized } \\
\text { Coefficients }\end{array}$} & \multirow{2}{*}{$\begin{array}{c}\text { Standardiz } \\
\text { ed } \\
\text { Coefficient } \\
\text { s } \\
\text { Beta }\end{array}$} & \multirow[t]{2}{*}{$\mathrm{t}$} & Sig. \\
\hline & & B & $\begin{array}{l}\text { Std. } \\
\text { Error }\end{array}$ & & & \\
\hline \multirow[t]{6}{*}{1} & (Consta & - & 1057,4 & & - & 7 \\
\hline & nt) & 343,67 & 45 & & ,32 & \\
\hline & & 7 & & & 5 & \\
\hline & Ukuran & 1,884 & 699 & ,631 & 2,6 & \\
\hline & & & & & 96 & \\
\hline & Umur & ,357 & ,070 & 1,192 & $\begin{array}{r}5,0 \\
94\end{array}$ & \\
\hline
\end{tabular}

Tabel di atas menunjukkan bahwa koefisien model regresi memiliki nilai constant sebesar 343,667 dengan nilai t hitung 0,325 dan nilai sig. sebesar 0,749.

Ukuran Perusahaan mempunyai t hitung sebesar 2,696 dengan probabilitas signifikansi adalah 0,015 dan nilai beta yang dihasilkan adalah positif sebesar 1,884. Hal tersebut menunjukkan bahwa probabilitas signifikansinya di bawah 0,05 .

Umur Perusahaan mempunyai t hitung sebesar 5,094 dengan probabilitas signifikansi adalah 0,000 dan nilai beta yang dihasilkan adalah positif sebesar 0,357 . 
Berdasarkan tabel 4.4 di atas maka didapatkan model persamaan regresi sebagai berikut:

$$
\mathrm{HS}=343,667+1,884(\mathrm{UKP})+0,357(\mathrm{UMP})
$$

Dimana:

$$
\begin{aligned}
& \mathrm{HS}=\text { Harga Saham } \\
& \text { UKP }=\text { Ukuran Perusahaan } \\
& \text { UMP = Umur Perusahaan }
\end{aligned}
$$

\section{PEMBAHASAN}

Hasil penelitian ini memberikan bukti bahwa bagi para investor, ukuran perusahaan dapat dijadikan salah satu patokan dalam melihat kualitas perusahaan. Oleh karena itu investor dapat mempertimbangkan ukuran perusahaan dalam menilai emiten yang melakukan IPO. Dalam dunia bisnis yang identik dengan persaingan, Perusahaan yang mempunyai kemamuan besar atau Ukuran Besar terutama dalam hal ini adalah asset yang dimiliki. Hal ini juga akan dapat membantu perusahaan yang mempunyai skala besar mampu mengatasi masalahmasalah yang ada terutama dalam hal financial atau dapat mengatasi finansial distress yang kerap terjadi pada perusahan-perusahaan saat.

Sedangkan untuk umur perusahaan yang menggambar tentang lamanya suatau perusahaan itu berdiri yang dimana dapat kita ketahui bersama bahawa semakin lama perusahaan itu berdiri maka semakin baik hal ini juga di sebabkan karena perusahaan tersebut telah mengalamai beberapa tantangan-tangan yang ada dan mengahadapi segala kondisi yang ada dari penelitian ini juga terlihat bahwa semakin lama perusahaan itu telah tumbuh aatau berjalan maka harga sahamnya juga akan meningkat.

\section{KESIMPULAN}

Penelitian ini bertujuan untuk meneliti pengaruh Ukuran Perusahaan Dan Umur Perusahaan terhadap Harga Saham Perusahaan yang melakukan IPO Berdasarkan dari hasil penelitian yang dilakukan maka peneliti menarik kesimpulan sebagai berikut :

1. Ukuran Perusahaan berpengaruh Positif dan signifkan terhadap Harga Saham

2. Umur Perusahaan berpengaruh Positif dan signifkan terhadap Harga Saham 
Kunuz: Journal of Islamic Banking and Finance Vol. 1, No. 1 (2021): 44-52 Website: http://ejournal.iain-manado.ac.id/index.php/kunuz

\section{DAFTAR PUSTAKA}

Abdullah, Y. R. (2018). Faktor-Faktor yang Mempengaruhi Underpricing pada Perusahaan yang Melakukan Initial Public Offering (IPO) di Bursa Efek Indonesia (BEI). STIE YKPN.

Ahmad, S. (2018). Anaylsis Of Initial Stock Underpricing Phenomenon At Indonesia Stock Exchange. Tasharruf: Journal Economics and Business of Islam, 3(1).

Armereo, C., Rahayu, P. F., \& Basri, H. (2020). Privatisasi dan Dampaknya Terhadap Kinerja Keuangan Badan Usaha Milik Negara (BUMN) di Bursa Efek Indonesia. Jemasi: Jurnal Ekonomi Manajemen Dan Akuntansi, 16(2), 48-60.

Ghozali, I. (2001). Aplikasi Analisis Multivariate dengan Program SPSS. Semarang: Badan Penerbit Universitas Diponegoro.

Hendrasih, I. (2017). Strategi Membeli Initial Public Offering (IPO) Di Pasar Modal Perdana Indonesia. Jurnal Moneter, 4(2), 166-168.

Hermuningsih, S. (2012). Pengaruh profitabilitas, size terhadap nilai perusahaan dengan sruktur modal sebagai variabel intervening. Jurnal Siasat Bisnis, $16(2)$.

Junaeni, I. (2013). Analisis Faktor-faktor yang Mempengaruhi Tingkat Underpricing Saham Pada Perusahaan yang Melakukan Initial Public Offering di BEI. Jurnal Ilmiah WIDYA, 1(1), 52-59.

Khairan, K. (2019). Kontribusi Pasar Modal Syariah dalam Pertumbuhan Ekonomi Indonesai. Jurnal At-Tamwil: Kajian Ekonomi Syariah, 1(1), 98114.

Putranto, A. D., \& Darmawan, A. (2018). Pengaruh Ukuran Perusahaan, Profitabilitas, Leverage, Dan Nilai Pasar Terhadap Harga Saham (Studi Kasus Pada Perusahaan Pertambangan Yang Terdaftar Di Bursa Efek Indonesia Periode 2010-2016). Jurnal Administrasi Bisnis, 56(1), 100-109.

Savira, R., \& Rimbano, D. (2016). Pengaruh Suku Bunga Dan Kurs Terhadap Harga Saham Perusahaan Real Estate Dan Property (Kajian Empiris Pada Bursa Efek Indonesia) Periode Bulanan 2013-2014. MOTIVASI: Jurnal Manajemen Dan Bisnis, 1(1), 25-36. 